\title{
Bahasa dan Integrasi Bangsa Dalam Kajian Antropologi- Fungsional
}

\author{
Nugroho Trisnu Brata \\ Fakultas IImu Sosial, Universitas Negeri Semarang (UNNES)
}

\begin{abstract}
Abstrak: Tulisan ini berusaha mengkaji fungsi atau peran bahasa dalam proses integrasi Bangsa Indonesia. Tulisan ini mengangkat permasalahan, yaitu bagaimana proses Bahasa Indonesia dimodifikasi dan diadopsi menjadi bahasa persatuan yang berfungsi sebagai perekat keberagaman etnik? Tujuan penulisan artikel ini adalah berusaha menjawab permasalahan bagaimana proses Bahasa Indonesia dimodifikasi dan diadopsi menjadi bahasa persatuan sehingga bisa beradaptasi dengan perubahan jaman. Landasan teori yang digunakan dalam melakukan analisis di sini adalah teori antropologi-fungsional yang dikembangkan oleh dua antropolog Inggris yaitu Bronislaw Malinowski dan Radcliffe Brown. Hasil bahasan menunjukkan bahwa Bahasa Indonesia memiliki karakter khusus yang berbeda dengan bahasabahasa bangsa lain karena Bahasa Indonesia berakar dari tradisi etnik lokal. Apabila Bahasa Indonesia tetap diperlukan sebagai bahasa yang bisa menjaga integrasi negara Indonesia maka harus ada sosialisasi dan pewarisan. Sosialisasi Bahasa Indonesia baku secara massal dan berkesinambungan misalnya dilakukan oleh TVRI atau TV-TV swasta yang menggunakan bahasa baku dalam siarannya. Bahasa Indonesia yang difungsikan sebagai bahasa persatuan bagi masyarakat Indonesia telah menciptakan fenomena bahasa berdampingan dengan fenomena politik, dalam hal ini adalah politik-kebahasaan. Sebagai saran, bahwa Bahasa Indonesia baku bisa menjadi salah satu unsur dalam menjaga integrasi Bangsa Indonesia, maka harus dilakukan sosialisasi dan pewarisan yang tiada henti.
\end{abstract}

Kata kunci: bahasa, integrasi, antropologi-fungsional.

\begin{abstract}
The writing attempts to analyze the functions or roles of language during the integration process of Indonesia. It raises a question on how the process of Indonesian language is modified and adopted into a language of unity functioning as the glue that holds the ethnic diversity. The article aims at discovering the process of modification and adoption of Indonesian language into the language of unity which is adaptable to the era changes. Theoretical background employed in the analysis is FunctionalAnthropology Theory developed by two British anthropologists, Bronislaw Malinowski and Radcliffe Brown. The results conclude that Indonesian language possess special characteristics which are different from other languages because it has its roots in local ethnics. If Indonesian language is permanently to be a language of unity, it is necessary to conduct socialization and inheritance. The socialization of Standard Indonesian language is massively and continuously conducted by TVRI or private television stations using standard language in their programs. The function of Indonesian language as the language of unity for Indonesian people has created language phenomenon and political phenomenon, side by side, in this case language politics. As a suggestion, continuous socialization and inheritance is necessary to be conducted due to the potency of Standard Indonesian language as one element in preserving the integration of Indonesia.
\end{abstract}

Key words: language, integration, and functional-anthropology 


\section{Pendahuluan}

Etnik atau ethnic groups secara umum dipahami sebagai masyarakat suku, atau masyarakat yang secara tradisi memiliki persamaan identitas. Wujud identitas itu misalnya bahasa, tempat tinggal, pola kekerabatan, pola perkawinan, religi, arsitektur rumah, pola tempat tinggal, dan lain-lain.

Mengenai bahasa maka makalah ini berusaha mengkaji fungsi bahasa baik secara konseptual maupun secara praksis. Bahasa sebagai salah satu identitas, di mana bahasa bisa menjadi identitas kolektif etnik, tetapi bahasa bisa juga menjadi identitas yang lebih luas dari etnik yaitu bangsa. Ciri yang menonjol dari identitas bangsa Indonesia tercermin dari adanya bahasa persatuan yaitu bahasa Indonesia. Walaupun dalam perkembangannya secara historis bahasa Indonesia yang baru muncul pada tahun 1928 dalam peristiwa Sumpah Pemuda kemudian mendapat beragam pengaruh kosa kata dari berbagai bahasa, akan tetapi bahasa Indonesia memiliki akar tradisi etnik yaitu bahasa Melayu.

Fenomena ini berbeda misalnya dengan Philipina yang memiliki 2 bahasa nasional yaitu bahasa Tagalog dan bahasa Inggris (Amerika), atau India yang bahasa nasionalnya adalah bahasa Inggris, atau Negara Aljazair yang bahasa nasionalnya bahasa Perancis, atau Singapura yang bahasa nasionalnya bahasa Inggris dan meninggalkan bahasa nenek moyangnya yaitu bahasa Melayu. Akar budaya kaum kolonial yang tercermin di dalam bahasanya itulah kemudian yang menjiwai negara-negara tersebut di muka yang telah mengadopsi bahasa bekas negara penjajahnya untuk dijadikan bahasa persatuan sebagai perekat etnik.

Permasalahan yang menjadi pertanyaan di sini adalah, bagaimana proses Bahasa Indonesia dimodifikasi dan diadopsi menjadi bahasa persatuan yang berfungsi sebagai perekat keberagaman etnik? Bahasa Indonesia memiliki karakter khusus yang berbeda dengan bahasabahasa bangsa lain karena dia berakar dari tradisi etnik lokal.

Tujuan penulisan artikel ini adalah berusaha menjawab permasalahan bagaimana proses Bahasa Indonesia dimodifikasi dan diadopsi menjadi bahasa persatuan yang bisa beradaptasi dengan perubahan jaman. Selanjutnya tulisan ini juga mengkaji kasus pemanfaatan Bahasa Indonesia sebagai bahasa pengantar pada siaran televisi-televisi yang siarannya berjangkauan nasional.

Bahasa Indonesia bersifat fleksibel dan ini tampak dalam berbagai dialek misalnya bahasa Indonesia dialek Betawi, dialek Sulawesi Selatan, dialek Palembang, dialek Papua dll, dan menurut de Saussure (1996: 80) hal ini adalah aspek parole dari bahasa. Bahasa Indonesia baku (ejaan yang disempurnakan/EYD) dalam konteks Saussurian disebut sebagai aspek langue. Langue-lah yang menjadi titik tekan kajian ilmu linguistik, langue merupakan fakta sosial yang artinya dia menjadi milik kolektif sistem dan berada di atas fakta individu. Parole adalah fakta individu. Sosialisasi Bahasa Indonesia baku secara massal dan berkesinambungan misalnya dilakukan oleh TVRI atau TV-TV swasta yang menggunakan bahasa baku dalam siarannya.

\section{Kajian Literatur dan Pembahasan}

Di dalam ilmu sosial-budaya khususnya ilmu antropologi apabila mengkaji fenomena sosial dengan perspektif fungsi atau peran maka mau tidak mau akan menyandarkan pijakan paradigma pada pendekatan fungsionalisme atau antropologi-fungsionalisme.

Sebagaimana dikemukakan oleh Kaplan \& Manners (2000: 77-78), "Fungsionalisme sebagai perspektif teoritik dalam antropologi bertumpu pada analogi dengan organisme/makhluk hidup. Artinya, sistem sosial-budaya dianalogikan sebagai sistem organisme, yang bagianbagiannya atau unsur-unsurnya tidak hanya saling berhubungan melainkan juga memberikan peranan bagi pemeliharaan, stabilitas, integrasi, dan kelestarian hidup organisme itu. Dengan analogi seperti itu maka semua sistem budaya memiliki syarat-syarat fungsional, atau sistem budaya memiliki kebutuhan sosial yang harus dipenuhi agar sistem sosial-budaya dapat bertahan hidup. Apabila kebutuhan itu tidak terpenuhi maka sistem sosial-budaya itu akan mengalami disintegrasi dan mati, atau dia akan berubah menjadi sistem lain tetapi beda jenis".

Pendekatan antropologi-fungsionalisme ini dikembangkan oleh dua orang antropolog Inggris yaitu Bronislaw Malinowski dan Radcliffe Brown 
(Kuper, 1996; 40). Dengan mengacu pada pendekatan fungsional itu maka stabilitas dan integrasi sistem sosial-budaya sangat tergantung pada fungsi dari unsur-unsur yang menjadi bagian dari sistem. Kalau suatu sistem organisme/ makhluk hidup itu unsur-unsurnya adalah kaki, mata, telinga, tangan, mulut, atau hidung maka sistem sosial-budaya yang bernama negara (sebagai contoh) unsur-unsurnya akan terdiri dari pemerintah, birokrasi, aparat keamanan, wilayah, bahasa, mata uang, atau penduduk. Semua unsur tersebut tidak hanya saling berhubungan akan tetapi juga saling menyumbangkan fungsinya masing-masing agar integrasi sistem tetap terjaga. Apabila salah satu unsur mengalami disfungsi atau tidak mampu menyumbangkan peran sesuai kapasitasnya, maka akibatnya akan dirasakan oleh unsur-unsur yang lain. Pada akhirnya integrasi sistem akan goncang. Salah satu kelemahan dari pendekatan fungsionalisme ini adalah pada asumsinya bahwa kondisi sistem sosial-budaya itu selalu dalam keadaan stabil dan terintegrasi. Pendekatan fungsional tidak mampu menjelaskan adanya perubahan sistem sosial budaya secara menyeluruh. Hal ini wajar karena semua pendekatan teoritik selalu memiliki kelebihan dan kekurangan.

Sistem sosial-budaya yang bernama negara, yaitu negara Indonesia unsur-unsurnya terdiri dari pemerintah, bangsa, wilayah, bahasa, atau penduduk. Dalam kajian ini diambil unsur bahasa.

Bahasa Indonesia berfungsi sebagai bahasa resmi kenegaraan, bahasa persatuan, sekaligus menjadi identitas bangsa Indonesia. Apabila Bahasa Indonesia sebagai unsur dari sistem negara pada suatu saat tidak mampu memberikan fungsinya sebagai bahasa resmi kenegaraan, bahasa persatuan, atau identitas bangsa maka akan terbayangkan adanya kegoncangan sistem sosial-budaya. Dalam peristiwa kenegaraan pasti akan terjadi kekacauan karena tidak ada bahasa kenegaraan. Semua orang akan membenarkan bahasa yang mereka gunakan sesuai etnisnya walau masing-masing berbeda bahasa. Tidak akan ada bahasa persatuan yang menjadi bahasa pengantar bagi masyarakat Indonesia yang memiliki latar belakang etnis dan bahasa beraneka macam. Tidak akan ada bahasa yang dijadikan identitas kebersamaan bahwa semua unsur itu menjadi bagian dari sistem yang bernama negara Indonesia. Inilah yang disebut sebagai disintegrasi atau distabilitas sistem negara.

Sebagai identitas bangsa atau negara maka bahasa Indonesia menjadi ciri atau tanda yang membedakan dengan bangsa lain atau negara lain. Identitas ini bisa saja menjadi salah satu faktor kebanggaan pada sebuah bangsa, yang kadang-kadang diiringi dengan sikap merendahkan atau menganggap aneh identitas bangsa lain. Identitas ini tidak stabil atau baku akan tetapi selalu berproses lewat wacana untuk berkomunikasi, sehingga identitas selalu terjaga, dinamis, berubah, atau malah musnah. Berawal dari merosotnya atau musnahnya kebanggaan akan identitas yang berupa Bahasa Indonesia maka bisa jadi ini adalah awal dari disintegrasi negara Indonesia. Tidak ada lagi alat komunikasi sesama warga Indonesia yang menjadi kebanggaan bersama, masing-masing merasa bangga dengan bahasa daerahnya atau bangga dengan bahasa manca negara sehingga bahasa Indonesia akan ditinggalkan.

\section{Bahasa Indonesia dan Siaran Televisi Nasional}

Apabila Bahasa Indonesia masih tetap diperlukan sebagai salah satu identitas kebersamaan bagi warga negara Indonesia maupun bahasa persatuan yang bisa menjaga integrasi negara Indonesia maka harus ada sosialisasi dan pewarisan (transmission). Beberapa cara bisa dilakukan untuk hal itu dan salah satu cara yang diungkapkan di sini adalah peranan stasiun televisi bersiaran nasional baik milik pemerintah (TVRI) maupun milik swasta (RCTI, SCTV, Indosiar, TPI, ANTV, Metro TV, dlI). Tidak semua materi siaran televisi itu selalu menggunakan bahasa Indonesia baku, yang oleh de Saussure (1996:360-361) disebut sebagai aspek langue dari bahasa. Bahasa dalam siaran televisi ini menarik untuk dikaji karena menjadi bagian dari dinamika masyarakat di Indonesia.

Teknologi canggih bernama televisi yang berbasis pada media satelit palapa ini mulai muncul di Indonesia pada tahun 1960-an. Fenomena sosial-budaya yang begitu banyak dan begitu luas kemudian "bisa dilipat-lipat" untuk dihadirkan di dalam ruang-ruang yang sempit sekalipun seperti 
ruang keluarga di dalam rumah. Teknologi televisi beserta hard ware-nya menjadi salah satu media transformasi dari dunia yang luas kemudian bisa hadir di tengah-tengah ruang keluarga. "Dunia yang begitu luas dan besar kini bisa 'dilipat-lipat' dalam bentuk televisi, surat kabar, majalah, internet, dan radio sehingga bisa hadir di tengahtengah keluarga dan di ruang yang sempit sekalipun" (Piliang, 1999).

TVRI selama puluhan tahun menjadi pemain tunggal stasiun penyiaran televisi di Indonesia yang telah menjangkau berbagai pelosok Indonesia. Baru pada paruh kedua tahun 1980an mulai muncul stasiun televisi swasta di Jakarta dengan siaran lokal yaitu RCTI. Setelah itu muncul stasiun TPI, SCTV, Indosiar dan lain-lain yang jangkauan siarannya berskala nasional seperti halnya TVRI. Walaupun begitu dalam hal misi, TVRI lebih terlihat sebagai stasiun televisi yang lebih mengedepankan aspek nonkomersial dengan meniadakan siaran iklan, yang kemudian disusul dengan membatasi siaran iklan. Sumber operasional TVRI berasal dari dana pemerintah dan hak siar iklan dari televisi-televisi swasta. Slogan "TVRI menjalin persatuan dan kesatuan" bukanlah sekedar jargon yang tanpa arti. Di balik slogan ini terkandung semangat untuk menjadi agen atau media perekat bagi berbagai etnis di Indonesia agar tetap dalam kondisi terintegrasi, tidak terpecah-belah. Slogan TVRI itu hampir mirip dengan slogan "sekali di udara tetap di udara" milik Radio Republik Indonesia (RRI) yang menyimpan semangat untuk terus mengudara melakukan siaran walau segenting apa pun keadaan negara. Kalau masyarakat Indonesia dalam kondisi selalu terpisahkan oleh ruang dan waktu dengan saudara-saudaranya sesama warga Indonesia yang lain maka siaran berita televisi berusaha menjadi media pemersatu ke dalam "waktu yang sama", dan seolah-olah para pemirsa televisi berada di dalam "satu ruang yang sama". Ada kelebihan pada siaran TV jika dibandingkan dengan siaran radio. Siaran radio hanya menyuguhkan aspek audio sehingga masyarakat hanya bisa mendengar tanpa bisa melihat wajah dan ekspresi penyiar radio. Siaran televisi selain bersifat audio juga ada aspek visual sehingga masyarakat bisa mendengar dan sekaligus melihat wajah dan ekspresi sang penyiar televisi. Dari hal ini muncul kesan seolaholah antara penyiar televisi dengan masyarakat pemirsa berada di dalam suatu "ruang dan waktu" yang sama.

Pada hal-hal tertentu TVRI bisa dianggap sebagai salah satu simbol pemersatu bagi masyarakat Indonesia melalui siaran-siarannya yang ditujukan kepada seluruh masyarakat Indonesia, atau masyarakat Indonesia di negara tetangga yang masih bisa menangkap siaran TVRI. Arti simbol menurut Folley (1997: 26); "A simbol is a sign in which the relationship between its form and meaning is stricly conventional, neither due to physical similarity or contextual constraints". Jadi, sebuah simbol adalah sesuatu yang akan memiliki makna apabila dihubungkan dengan hal yang lain. Pemberian makna ini akan mengacu pada konteks sosial-budaya masyarakat si pemilik simbol. Dapat terjadi sesuatu itu oleh sekelompok masyarakat dianggap sebagai simbol yang penuh makna, akan tetapi oleh masyarakat yang lain dianggap tidak memiliki makna apa-apa atau hampa makna. TVRI bisa dianggap sebagai salah satu simbol pemersatu bagi masyarakat Indonesia karena dia mampu menyebarkan informasi dengan bahasa Indonesia ke seluruh pelosok negara. Bahasa Indonesia adalah bahasa pengantar bagi masyarakat Indonesia yang berbeda etnis maupun bahasa ibu, sebagai bahasa resmi kenegaraan termasuk bahasa dokumen atau arsip maupun buku-buku pelajaran di sekolah, dan bahasa resmi bagi penyebaran informasi di media massa. TVRI memiliki makna mendalam karena dihubungkan dengan keberadaan bahasa Indonesia maupun keberadaan bangsa Indonesia. TVRI menjadi simbol jembatan bagi masyarakat Indonesia yang secara geografis maupun kultural adalah masyarakat majemuk.

Media televisi, terutama dalam siaran berita misalnya TVRI (siaran Dunia dalam Berita, Berita Malam), RCTI (siaran Nuansa Pagi, Buletin Siang), Indosiar (siaran Fokus), SCTV (siaran Liputan 6 pagi, Liputan 6 Siang) dan lain-lain, kalau diamati para penyiarnya menggunakan bahasa Indonesia baku. Akan tetapi dalam berbagai siaran yang lain misalnya berbagai siaran iklan, pertunjukan musik, siaran kuis, atau siaran kesenian maka akan terlihat bahasa pop atau "bahasa gaul" dengan berbagai varian menjadi bahasa 
pengantar. Di sini bisa dilihat adanya aspek langue (pada bahasa berita) sekaligus adanya aspek parole (pada berbagai siaran yang lain) dalam siaran televisi di Indonesia. Yang kemudian menjadi pertanyaan adalah mengapa dalam siaran berita menggunakan bahasa Indonesia baku, sedangkan dalam siaran yang lain menggunakan bahasa pop ? Tentu tidak akan mudah untuk menjawabnya secara rasional, sistematis, dan jernih.

Fenomena bahasa berita di media televisi ini menarik untuk dikaji karena pada tingkatan tertentu bahasa berita bisa meng-hegemoni sebagian masyarakat pemirsa televisi sehingga mereka harus mengikutinya (melihat, mendengar, membenarkan dan memperbincangkan). Hegemoni sendiri sering diartikan sebagai kekuasaan yang dicapai melalui kesepakatan dan bukan paksaan. Daya jangkau hegemoni sangat dalam, mencakup pikiran dan perasaan masyarakat, beroperasi di wilayah publik serta wilayah domestik. Hegemoni sering dibedakan dengan dominasi, di mana dominasi diartikan sebagai kekuasaan yang dicapai melalui paksaan dan kekerasan, daya jangkau kekuasaan dominasi hanya sampai permukaan. Hegemoni secara halus menuntun orang untuk bersikap atau berperilaku sesuai dengan pemegang kekuasaan hegemoni bahkan kadang-kadang orang tidak merasa terpaksa atau melakukan sesuatu dengan suka rela. Kekuasaan dominasi itu dilakukan secara paksaan, orang sanggup bersikap atau berperilaku sesuai dengan pemegang kekuasaan dominasi karena daya resistensi orang tersebut kalah kuat dari daya paksa pemegang dominasi. Bahasa siaran berita televisi beroperasi pada wilayah hegemoni, akan tetapi pada saat tertentu juga beroperasi pada wilayah dominasi. Contoh dari dominasi ini adalah saat sang pembaca berita memerintahkan kepada pemirsa, "Jangan kemana-mana dulu karena kami akan hadir lagi setelah jeda iklan berikut ini" atau "Tetaplah bersama saluran kami". Kalimat-kalimat imperatif dan "tembak langsung" ini sering kita jumpai pada siaran berita di televisi.

Di dalam membacakan berita maupun format penghadiran berita maka juga bisa dilihat adanya aspek seni. Sentuhan seni ini juga menjadi daya tarik khalayak untuk menyaksikan siaran berita televisi. Dari sini terlihat, seni telah dimanfaatkan oleh para pembaca berita pada siaran televisi untuk mengkomunikasikan berbagai hal yang berhubungan dengan informasi kepada khalayak pemirsa televisi. Mengenai makna seni, maka dapat diperhatikan pendapat dari Taufik Abdullah, "...pada tahap awal seni adalah suatu pilihan dari berbagai cara untuk melukiskan dan mengkomunikasikan sesuatu. Setiap bentuk seni sesungguhnya adalah perkembangan dari caracara yang biasa dilakukan dalam hidup manusiasajak tentu berawal dari ucapan dan tarian tentu berawal dari gerakan" (Abdullah, 1980/1981). Keinginan para pembaca berita di televisi untuk mendapat perhatian dan tawaran ketertarikan menyaksikan berita, dikomunikasikan kepada masyarakat pemirsa melalui seni membaca berita. Seni menjadi media yang dimanfaatkan untuk menghadirkan pesona siaran berita.

\section{Integrasi Sosial}

Dengan mengutip pandangan dari de Saussure, Cassirer (1987: 186) mengatakan bahwa, "de Saussure menarik garis tajam antara la langue dengan la parole. Bahasa (la langue) bersifat universal sedangkan proses tuturan (la parole) sebagai proses temporal dan bersifat individual. Setiap individu memiliki gaya bahasa sendiri. Akan tetapi dalam analisis ilmiah tentang bahasa, perbedaan-perbedaan individual diabaikan dan ditelaah fakta sosial yang mengikuti kaidah-kaidah umum yaitu kaidah-kaidah yang tidak tergantung kepada si penutur individual. Tanpa kaidah-kaidah umum seperti itu maka bahasa tidak akan dapat menunaikan tugas utamanya; bahasa tidak dapat dipakai sebagai media komunikasi di antara anggota-anggota masyarakatnya". Dari kutipan ini terlihat bahwa langue yang memiliki kaidahkaidah umum adalah fakta sosial, yang posisinya lebih tinggi dari fakta individu. Fakta sosial ini beroperasinya adalah lintas individu dan bersandar pada kaidah-kaidah umum bahasa, agar bahasa bisa menjadi media komunikasi sosial.

Langue yang memiliki sifat sebagai media komunikasi sosial bahkan pada tataran tertentu mampu menjadi media integrasi sosial lewat siaran berita televisi. Bahkan, pada fenomena kehidupan bernegara langue juga bisa bersifat politis. Seperti yang ditulis oleh Eriyanto (2000: 
74-75), "Pada tahun 1974 pemerintah melalui Rencana Pembangunan Lima Tahun (REPELITA II) juga mencakup sasaran khusus untuk pengembangan bahasa, sastra, dan kebudayaan. Pada tahun 1974 dibentuk proyek Pengembangan Bahasa dan Sastra Indonesia dan Daerah. Pada tahun 1984 proyek ini dibagi menjadi dua bagian yaitu Proyek Pengembangan Bahasa dan Sastra Indonesia dan Proyek Pengembangan Bahasa dan Sastra Daerah. Salah satu perhatian utama dari kebijakan bahasa oleh pemerintah adalah mengadakan pembakuan bahasa Indonesia dan menerapkan serta menghimbau 'pemakaian bahasa yang baik dan benar'. Perundangan kebijakan ini dituangkan di dalam Ketetapan MPR No.II/MPR/1983 yang menyatakan bahwa bahasa harus dibina dan dikembangkan serta digunakan secara baik dan benar".

Langkah pemerintah merupakan usaha untuk menjaga integrasi bangsa Indonesia lewat kebijakan bahasa Indonesia. Kebijakan ini tentu berdampak terhadap berbagai segi kehidupan masyarakat karena bahasa Indonesia yang dibakukan kemudian menjadi referensi tentang penggunaan bahasa Indonesia yang baik dan benar. Penulisan dalam berbagai surat keputusan, surat- menyurat resmi, arsip-arsip birokrasi, acara protokoler, bahasa pengantar di lembaga-lembaga pendidikan, siaran-siaran resmi di televisi atau di radio adalah realitas sosial yang secara langsung akan mengikuti kebijakan bahasa oleh pemerintah.

Kebijakan pemerintah ini bukannya berjalan mulus tanpa hambatan. Sebagian kaum akademisi secara kritis dan tajam mengoreksi kebijakan bahasa dari pemerintah ini. Contoh dari mereka ini adalah Hooker (1993: 273) dan Heryanto (1992: 9), yang mengatakan bahwa penggunaan bahasa yang baik dan benar adalah salah satu bentuk manipulasi pemerintah untuk mengukuhkan kekuasaan terhadap rakyat. Bahasa yang baik dan benar bisa dianggap sebagai simbol adanya pusat kebenaran yang harus memiliki kewibawaan, di mana semua kebijakannya harus ditaati oleh masyarakat. Bahasa yang baik dan benar adalah yang digunakan oleh pemerintah sedangkan yang digunakan oleh masyarakat adalah sebaliknya sehingga masyarakat harus mengikuti pusat kebenaran yaitu pemerintah.
Pembakuan bahasa, oleh kalangan pengritik juga dianggap sebagai pengingkaran terhadap dinamika sosial-masyarakat sebab bahasa adalah bagian dari sebuah dinamika sosial-masyarakat yang sifatnya natural (alamiah). Dari hal ini kita bisa melihat bahwa fenomena bahasa Indonesia juga tidak bisa dipisahkan dari nuansa politik dalam kehidupan bernegara. Bahasa Indonesia yang diposisikan sebagai bahasa persatuan bagi masyarakat Indonesia secara otomatis telah menciptakan fenomena bahasa berdampingan dengan fenomena politik, dalam hal ini adalah politik kebahasaan.

Mengenai bahasa yang identik dengan dinamika sosial-masyarakat ini juga bisa ditelaah dari pandangan de Saussure $(1996 ; 361)$ bahwa "Di antara etnis dan langue terjadi hubungan timbal balik. Hubungan sosial cenderung menciptakan adanya masyarakat bahasa dan kemungkinan mencetak ciri-ciri tertentu pada langue yang dipakai. Sebaliknya, masyarakat bahasalah yang dalam batas-batas tertentu juga bisa membentuk satuan etnis. Pada umumnya satuan etnis cukup menjelaskan tentang masyarakat bahasa". Dari kutipan tersebut, terlihat bahwa bahasa adalah ciri yang menonjol dan mudah diamati dari suatu masyarakat. Bahasa tertentu identik dengan masyarakat tertentu, misalnya bahasa Bali identik dengan etnis Bali atau bahasa Bugis akan identik dengan etnis Bugis. Jadi, bahasa mampu menciptakan etnis. Begitu juga sebaliknya ternyata bahasa menjadi ada karena diciptakan oleh suatu etnis. Misalnya, bahasa Indonesia menjadi ada karena diciptakan oleh masyarakat Indonesia, walau fondasinya adalah bahasa Melayu akan tetapi dua bahasa itu kemudian memiliki perbedaanperbedaan. Fenomena inilah yang biasa disebut sebagai bahasa dan dinamika masyarakat. Bisa juga dikatakan bahwa bahasa sebenarnya adalah dinamika masyarakat itu sendiri. Karena adanya suatu dinamika masyarakat di Indonesia maka bahasa Indonesia yang digunakan pada masa perjuangan tahun 1945-1949 memiliki karakter heroik sedangkan pada masa pemerintahan Orde Baru bahasa Indonesia karakternya sarat dengan eufemisme atau penghalusan kata untuk menyembunyikan makna yang sesungguhnya. Lain lagi karakter bahasa Indonesia pada masa 
puncak reformasi tahun 1998 hingga 1999 yang syarat dengan hujatan, caci-maki, dan pembongkaran aib mantan penguasa.

Fenomena kebahasaan pada tahun 19981999 itu bisa disaksikan pada berbagai liputan berita (bukan pembacaan siaran berita) stasiunstasiun televisi tentang peristiwa yang terjadi di lapangan. Begitu cepatnya berita-berita tentang kerusuhan sebagai ekses proses peralihan kekuasaan di Jakarta dan beberapa kota di Jawa kemudian menyebar ke seluruh pelosok Indonesia. Pada sisi kecepatan penyampaian berita sehingga menyebar kepada masyarakat Indonesia juga bisa dilihat bahwa siaran berita televisi bisa menjadi media pembangun integrasi sosial karena masyarakat luas tidak tersekat atau terpisahkan oleh ruang dan waktu.

\section{Simpulan dan Saran}

\section{Simpulan}

Pada bagian ini dengan memperhatikan uraian di muka dapatlah ditarik sebuah benang merah yang berupa simpulan. Dengan mengambil kasus siaran berita yang menggunakan bahasa Indonesia baku pada stasiun televisi milik pemerintah yaitu TVRI maupun stasiun televisi swasta seperti RCTI, SCTV, Indosiar, TPI, ANTV, Metro TV dan lain-lain maka tulisan ini telah berusaha mengkaji fenomena bahasa dan dinamika masyarakat di Indonesia. Bahasa Indonesia baku yang digunakan dalam siaran berita berbagai stasiun televisi tersebut telah menjadi salah satu media integrasi sosial bangsa Indonesia. Siaran berita dengan bahasa Indonesia baku ini merupakan aspek langue dari kajian tentang siaran televisi. Langue beroperasi pada wilayah sosial dan bukannya pada wilayah individual, sehingga langue bisa disebut sebagai fakta sosial.

Realitas geografis masyarakat Indonesia dari
Sabang sampai Merauke terpisahkan oleh ruang dan waktu maka siaran televisi yang menggunakan bahasa Indonesia baku berperan menjadi media yang bisa mengintegrasikan mereka. Siaran televisi menjadi media pemersatu ke dalam "waktu yang sama" dan seakan-akan para pemirsa televisi berada di dalam "satu ruang yang sama".

Bahasa dan dinamika masyarakat adalah fenomena yang bersifat natural, akan tetapi bisa juga berubah menjadi fenomena politis karena adanya campur tangan dari penguasa. Bahasa kemudian dijadikan sebagai alat untuk mengontrol masyarakat dan lebih jauh lagi adalah untuk mengokohkan kekuasaan atau malah untuk mewujudkan integrasi sosial. Integrasi sosial bisa juga terjadi karena adanya identitas kebersamaan yang bisa menjadi pembeda dengan entitas sosial yang lain, yang kadang-kadang diikuti oleh kebanggaan terhadap entitas sendiri dan tidak jarang mengganggap remeh entitas sosial yang lain. Bahasa adalah salah satu simbol identitas kebersamaan yang bisa berfungsi untuk mewujudkan integrasi sosial.

\section{Saran.}

Sebagai saran, di dalam arus deras globalisasi maka integrasi Bangsa Indonesia pasti terkena dampaknya. Sekat-sekat pembatas dengan dunia luar baik aspek ideologi, politik, ekonomi, kebudayaan, gaya hidup, maupun kriminal menjadi terbuka. Sudah selayaknya berbagai cara dilakukan baik oleh pemerintah, pihak swasta, maupun masyarakat Indonesia secara luas untuk menjaga integrasi Bangsa Indonesia. Bahasa Indonesia baku bisa menjadi salah satu unsur dalam menjaga integrasi Bangsa Indonesia, maka harus dilakukan sosialisasi dan pewarisan yang tiada henti.

\section{Pustaka Acuan:}

Abdullah, Taufik. "Analisis Kebudayaan, tahun I; No.2 1980/1981: 11".

Cassirer, Ernst, 1987. "An Essay on Man" diterjemahkan ke dalam Bahasa Indonesia oleh Alois A. Nugroho. Jakarta: PT Gramedia.

de Saussure, Ferdinand, 1996. "Cours de Linguistique Generale" diterjemahkan ke dalam Bahasa Indonesia oleh Rahayu S. Hidayat dan disunting oleh Harimurti Kridalaksana. Yogyakarta: Gadjah Mada University Press. 
Eriyanto, 2000. "Kekuasaan Otoriter dari Gerakan Penindasan menuju Politik Hegemoni, Studi atas Pidato-Pidato Politik Soeharto". Yogyakarta: Pustaka Pelajar.

Folley, William A., 1997. "Anthropological Linguistics An Introduction". Malden USA: Balckwell Publishers Inc.

Heryanto, Ariel., 1992. "Pembakuan Bahasa dan Totalitarianisme", Kritis, Vol.8, No.1.

Hooker, Virginia Matheson, 1993. "New Order Language in Context" dalam Virginia Matheson Hooker (ed), Culture and Society in New Order Indonesia. Kuala Lumpur: Oxford University Press.

Kaplan, David \& Albert A. Manners, 2000. "The Theory of Culture" diterjemahkan ke dalam Bahasa Indonesia oleh Landung Simatupang. Yogyakarta: Pustakan Pelajar

Kuper, Adam, 1996. "Anthropology and Anthropologists" diterjemahkan ke dalam Bahasa Indonesia oleh Achmad Fedyani Saifuddin. Jakarta: Bhratara Karya Aksara

Piliang, Yasraf Amir, 1999. "Hiper-Realitas Kebudayaan". Yogyakarta: LKiS. 